The Family Pharm: An Ethical Consideration of Psychopharmacology in Couple and Family Counseling

By: Christine E. Murray and Thomas L. Murray Jr.

Murray, C. E., \& Murray, T. L. (2007). The Family Pharm: An ethical consideration of psychopharmacology in couple and family counseling. The Family Journal: Counseling and Therapy for Couples and Families, $15,65-71$.

Made available courtesy of Sage Publications: http://www.sagepub.com/home.nav

*** Reprinted with permission. No further reproduction is authorized without written permission from Sage Publications. This version of the document is not the version of record. Figures and/or pictures may be missing from this format of the document. $* * *$

Abstract:

This article presents an overview of ethical issues surrounding psychopharmacology as it applies to the field of couple and family counseling. The authors ground their discussion of these issues in the ethical codes of the American Counseling Association and the International Association of Marriage and Family Counselors. Case studies illustrate the ethical issues that couple and family counselors may face when working with clients who have been prescribed psychotropic medications.

Keywords: ethical issues; psychopharmacology; couple and family counseling; case studies; psychotropic medication and families

Article:

Recently, Crews and Hill (2005; Hill \& Crews, 2005) wrote about the ethical issues surrounding the diagnosis of mental disorders in couple and family counseling. An important related issue is the ethical context of the use of psychotropic medications by clients in couple and family counseling. In this article, we explore the ethical dilemmas that couple and family counselors may face when working with clients who take psychiatric medications. We begin with an overview of perspectives on psychotropic medication and relevant ethical standards. In a subsequent presentation of three case vignettes, we apply ethical standards to guide clinical decision making.

\title{
PERSPECTIVES ON PSYCHOTROPIC MEDICATIONS
}

The ethical issues surrounding the use of psychotropic medications for the treatment of mental health disorders are muddled in confusion, resulting from a high degree of controversy among various groups of professionals surrounding the benefits and risks of these medications (King \& Anderson, 2004; Prosky \& Keith, 2003). Space limitations preclude a comprehensive review of the research on psychotropic medication effectiveness, so readers are directed to the following literature reviews for more detailed information about the current state of this research: Aschenbrenner, 2005; Breggin \& Cohen, 1999; Chouinard, 2004; Jackson, 2005; Keefe, Silva, Perkins, \& Lieberman, 1999; Kirsch, Moore, Scoboria, \& Nicholls, 2002; Moncrieff, \& Kirsch, 2005; Murray, in press; and Schwartz, 2005. At minimum, couple and family counselors should become aware that there are two vastly different viewpoints on the safety and benefits of psychotropic medication, with additional viewpoints falling between the two extremes.

\section{Viewpoint: Medication as Primary Form of Treatment}

One perspective on psychotropic medications is that they are the primary treatment of choice for a wide array of mental health disorders. The use of psychotropic medications has been advocated as the first-line treatment for a number of psychiatric diagnoses, including attention deficit hyper-activity disorder (American Academy of Pediatrics, 2001), bipolar disorder (Shattell \& Keltner, 2004), mood disorders (Tremblay \& Blier, 2006), obsessive-compulsive disorder (Van Ameringen, Mancini, Patterson, \& Bennett, 2006), pre-menstrual dysphoric disorder (Steiner et al., 2006), schizophrenia (Canadian Psychiatric Association, 2005), and social anxiety disorder (Blanco, 2005). Reflecting this perspective, Shattell and Keltner (2004) wrote, "Managing 
symptoms through psychotropic medications can help people with mental illness better manage their lives" (p. 37).

\section{Viewpoint: Medications as Hazardous to Clients' Health}

The opposite perspective holds that psychotropic medications are dangerous, poorly studied, and potentially create more problems than they alleviate (Breggin, 1991; Breggin \& Cohen, 1999; Glasser, 2003; Glenmullen, 2000, 2005; Jackson, 2005; Murray, in press). Some scholars have suggested that psychotropic medications are overprescribed in cases in which psychotherapy would be more beneficial. According to Graybar and Leonard (2005),

By rejecting psychotherapy ... biological psychiatry has exchanged listening to people and their problems with listening for symptom clusters and hypothesized chemical imbalances. It can be of no surprise then that when a psychiatric resident's only tool is a hammer (i.e., a prescription pad), then every client issue becomes a nail (i.e., a chemical imbalance to be medicated). (p. 9)

Some empirical evidence suggests that psychotherapy can lead to greater reductions in mental health disorder symptoms as compared to treatment with psychotropic medications (Bovasso, Eaton, \& Armenian, 1999) and that the use of certain psychotropic medications (e.g., benzodiazepines) can minimize the effectiveness of counseling (Finn, 2001). Last, there are concerns regarding the inherent message surrounding the issue of medicating clients despite no independent proof of brain defects and the medical model in general (Hansen, 2005; Liburd \& Rothblum, 1995; Murray, in press). For example, psychiatrist Daniel Dorman (2003) wrote, "Declaring that someone has a disease of the mind that requires treatment with drugs is to tell her she has a permanent and profound flaw, that she will never join humanity" (p. 63).

\section{Viewpoint: Integrated Treatment Options}

Rather than an either/or position as described above, others have promoted an integrative approach (Preston, O’Neal, \& Talago, 2000). This approach holds that treatment will be guided by the unique needs and circumstances of the client. Within this integrative approach, medication is viewed as most helpful for some clients, psychotherapy is viewed as the most successful treatment for other clients, and a combination of medication and psychotherapy is seen as the most effective path to mental health for others. Many authors support this integrative approach (Chavira \& Stein, 2002; Hollon et al., 2005; Hollon, Thase, \& Markowitz, 2002; Lutova, 2002; Paradise \& Kirby, 2005; Trestman, 2004; Winston, Been, \& Serby, 2005).

Clients may experience varying degrees of uncertainty in their own beliefs about psychotropic medications, and their treatment may be more effective when it is matched to their preferences for psychotropic medications and/or psychotherapy (Lin et al., 2005). Our clinical experience has shown that some clients who demonstrate psychiatric symptoms want to be treated only with medications, others wish to be treated only with psychotherapy, and others wish for some combination of the two treatment modalities. Clients are likely to seek out the guidance of couple and family counselors as they consider the various options available to them to promote their mental and relational health.

\section{RELEVANT ETHICAL STANDARDS}

The ethical codes of the American Counseling Association (ACA; 2005) and the International Association of Marriage and Family Counselors (IAMFC; 2005) are useful tools in guiding the decision making of counselors who work with clients considering psychotropic drug use. Two ethical standards form the conceptual foundation for our discussion. First, the ACA Code of Ethics states, "The primary responsibility of counselors is to respect the dignity and to promote the welfare of clients" (Section A. 1.a). Couple and family counselors, therefore, hold an ultimate responsibility to promote the mental and relationship health of their clients, and this responsibility underlies all actions they take. Second, the IAMFC (2005) Ethical Code holds that, "Marriage and family counselors are knowledgeable about the roles and functions of other disciplines, especially in the helping professions such as psychiatry, psychology, social work, and mental health counseling" (Section D. 1). Based on this standard, couple and family counselors also maintain an ethical obligation to learn about and help their 
clients understand issues surrounding the prescription and use of psychotropic medications. Derived from these two ethical standards, we propose that couple and family counselors are responsible for developing their knowledge about the uses of psychotropic medications to assist their clients in understanding whether and how these medications can be helpful in promoting their own health and well-being.

The varying perspectives on the utility of psychotropic medications add to the complexity of the surrounding ethical issues. Therefore, a preliminary step for couple and family counselors to take is to examine their values and beliefs regarding the benefits, risks, and usefulness of psychotropic medications. Both the ACA Code of Ethics (2005) and the IAMFC Ethical Code (2005) stress the importance of counselors developing awareness of their values, biases, and beliefs. The situations described in the remainder of this article present opportunities for readers to begin to examine their beliefs and values surrounding these issues. In the following sections, we present three case studies that describe situations that may arise for couple and family counselors related to psychopharmacology. We discuss the situation in each case study as it relates to relevant ethical guidelines.

\section{CASE STUDY 1: MS. BROWN}

Ms. Brown arrived in the office of a couple and family counselor seeking a second opinion. She recently visited her family physician regarding complaints of heart palpitations, difficulty concentrating, muscle tension, and a frequent feeling of butterflies in her stomach. The physician ran blood tests and tested for cardiac abnormalities. The physician found no biological cause and suspected that the client was experiencing mild panic attacks. The physician wrote a prescription for Ms. Brown to take a low dose of an antianxiety medication with a plan to increase the dosage during the next few months depending on her symptom presentation. The physician provided Ms. Brown with a 2-week supply of free samples of the medication, which were left behind following a visit from a pharmaceutical sales representative. Although Ms. Brown expressed some reservations to the physician about taking the medication, her physician advised her that the medications would be "helpful in stopping her panic attacks."

Ms. Brown was disappointed that her physician did not take her reservations seriously, so she sought the guidance of the couple and family counselor for a second opinion. Ms. Brown chose to meet with the counselor for this second opinion because she desired an opinion from someone who was not a physician. "I'm afraid that any physician will be biased and definitely want me to take medicine," she said. In addition, she reported to the counselor that she had previously benefited from counseling and wondered if it might be helpful to her again.

\section{Commentary}

Three ethical standards are particularly relevant to this case study: competence, informed consent, and client autonomy.

Competence. The first relevant standard relates to competence. As stated in Section C.2.a of the ACA Code of Ethics (2005), "Counselors practice only within the boundaries of their competence, based on their education, training, supervised experience, state and national professional credentials, and appropriate professional experience." The counselor in this situation must evaluate his or her level of knowledge regarding psychotropic medications, particularly the medication prescribed to Ms. Brown, to determine whether it is appropriate to discuss this issue at all with Ms. Brown. If the counselor determines that he or she possesses sufficient knowledge to discuss the use of this medication, the counselor next must consider how much to say without practicing outside the boundaries of their competence and professional training. Ingersoll (2000) wrote that there are "no clear prohibitions against a nonmedical mental health professional talking with clients about psychotropic medications" (p. 67). Counselors are advised not to make specific recommendations about the use or nonuse of particular drugs. However, counselors are encouraged to know the current medications that clients are prescribed so that side effects can be monitored and reported when necessary.

Most counselors do not receive extensive training in psychopharmacology (Scovel, Christensen, \& England, 2002), and counselors are not able to prescribe medications to their clients. However, couple and family counselors are responsible for developing knowledge in areas that relate to their clinical practice (ACA, 2005, 
Section C.2.f; IAMFC, 2005, Section A, Introduction). Within ethical and professional boundaries, counselors may assist their clients in under-standing information that is available to them regarding the medications they may take. For instance, the counselor in this situation could talk with Ms. Brown about existing advertisements for the antianxiety medication prescribed, including the "fine print" written on the advertisement. This counselor should only take this step if he or she is knowledgeable about the definitions of terms and use of language contained within these advertisements.

Informed consent. The second relevant standard relates to informed consent. The ACA Ethical Code (2005, Section A.2.a) states, "Clients have the freedom to choose whether to enter into or remain in a counseling relationship and need adequate information about the counseling process and the counselor." Although counselors may not prescribe medications for their clients, this ethical standard suggests that clients have a right to be provided with broad information that will allow them to make informed decisions about all of their treatment alternatives. Psychotropic medications are often a component of treatment for mental health disorders - and often in conjunction with counseling (Beitman \& Saveanu, 2005). Counselors share some responsibility for ensuring that clients have access to the information needed to make these decisions, particularly when couple and family counselors work in interdisciplinary teams or work with clients who are also being seen by psychiatrists or physicians who prescribe psychotropic medications. The counselor should assist Ms. Brown in seeking and evaluating more information from medical journals and Web sites that discuss the research conducted on the effectiveness of the anti-anxiety medication, its side effects, and contraindications (Breggin \& Cohen, 1999). In particular, this counselor should (a) seek out information based on well-conducted studies by independent researchers who have no ties to the pharmaceutical industry and (b) be able to identify the frequent methodological problems associated with the psychopharmacology literature to critically evaluate the research (Safer, 2002).

Autonomy. Finally, in this situation it is important for the counselor to remind Ms. Brown that it is ultimately her decision regarding whether or not she wishes to take the medication (IAMFC, 2005, Section A.3). Within the boundaries of their professional competence and training, couple and family counselors should not make decisions about whether a client should take or not take a particular medication but rather help clients to locate and understand information that will help them to make appropriate decisions for themselves (IAMFC, 2005, Section A.3).

\section{CASE STUDY 2: TONY}

Tony is a 7-year-old second-grader at the local elementary school. His father brought him in to the local community mental health agency for psychiatric treatment. His father reported that Tony could not sit still in school, was "always on the go," and was disruptive and impatient at home and in school. The father also reported that "the other kids at school don't like Tony because he's always really bossy and not very nice to them." Tony's teacher had made several calls to Tony's parents because of his behavioral problems, and the teacher suggested that Tony go to the mental health agency to see if he could be helped there.

Tony was seeing the psychiatrist for 2 months before he arrived in the office of the couple and family counselor on staff at this agency. At his first meeting with the psychiatrist 2 months ago, the psychiatrist diagnosed Tony with attention deficit hyperactivity disorder - predominantly hyperactive-impulsive type and prescribed him a psychostimulant (examples of this class of drugs include Ritalin, Strattera, and Adderall) to be taken daily. Although Tony's parents believed that the medication had been helping somewhat, they requested for Tony to meet with a counselor for additional support. During the first meeting with the counselor, Tony and his father revealed that Tony was now "sleepy all of the time" and demonstrated extremely low energy. Tony's father stated, "Sure, he's not having any of his problems at school anymore, but he's also just not himself anymore. It's like this medicine just totally conked him out. His mother and I definitely don't want to start having all those problems at school and at home again, but we miss the old Tony."

The counselor reflected back to the clients, "It sounds as though you're beginning to wonder if these medications are worth it." The counselor began to notice himself becoming frustrated with this situation. The 
counselor had experienced some previous disagreements with the psychiatrist whom Tony was seeing, and he had come to believe that this particular psychiatrist overmedicated most of the clients she saw. This counselor was feeling uncertain about how to proceed with treatment with Tony. The counselor's initial beliefs were that Tony's medications were causing more harm than good and that systemic counseling interventions would be a more appropriate approach to treating his symptoms.

\section{Commentary}

Several relevant ethical issues arise based on the facts presented. The most significant ethical dilemma embedded within this case study involves how the counselor can best coordinate Tony's treatment with a psychiatrist with whom he has had previous disagreements. The ethical codes of both the ACA and the IAMFC emphasize the importance of counselors working to maintain positive relationships with individuals with whom they work as part of multidisciplinary treatment teams (ACA, 2005, Section D; IAMFC, 2005, Section D.1). It appears from this case study that the counselor and the psychiatrist hold different philosophical assumptions about the best course of treatment for clients like Tony. The counselor must first attempt to gain under-standing about the psychiatrist's beliefs, training, and experiences to understand her unique skills and treatment approaches. The ACA Code of Ethics (2005) states that "counselors are respectful of traditions and practices of other professional groups with which they work" (Section D.1.a). Therefore, this counselor's first step should be to try to learn more about the psychiatrist's reasons for prescribing the selected medication and her expectations for the ongoing treatment of Tony.

The counselor should attempt to communicate with the psychiatrist regarding treatment alternatives for Tony, as it is important for counselors to be involved in treatment decisions that involve how to best serve their clients (ACA, 2005, Sections D. 1.c and D. 1.e). The counselor should first inform Tony and his parents that he will be consulting with the psychiatrist as a member of the client's treatment team (ACA, 2005, Section B.3.b). A positive outcome of this communication with the psychiatrist would involve a coordinated treatment plan that combines the most effective strategies available from the psychiatrist and the counselor.

It is possible that a disagreement regarding the best treatment approach may arise between this counselor and the psychiatrist treating Tony, and this disagreement may not be able to be managed successfully. In this situation, the counselor must consider whether it is appropriate for him to continue counseling Tony and his family. The IAMFC (2005) Ethical Code states, "Marriage and family counselors have an obligation to withdraw from a counseling relationship if the continuation of services would not be in the best interest of the client or would result in a violation of ethical standards" (Section A. 10). It is possible that this counselor could not separate his personal feelings regarding the psychiatrist from his treatment objectives for this client. Conflict with the psychiatrist may result in inappropriate "splitting, triangulation, and indirect forms of communication" (IAMFC, 2005, Section D.6). Examples of these unethical behaviors in this situation could include speaking negatively about the psychiatrist with the client or providing only negative information about the medications that the client has been pre-scribed to convince Tony and his family that he should no longer be taking them. Because of the potential for ethical violations in this situation, the counselor should seek consultation from a colleague who is knowledgeable about counseling ethics to determine the most appropriate course of action if a conflict with the psychiatrist cannot be resolved (ACA, 2005, Section H.2.d). If it becomes clear that it is not in Tony's best interest to continue to receive counseling from this counselor, appropriate referrals should be made to assist the client in receiving needed services elsewhere (ACA, 2005, Section A. 1 1.d).

Another possibility in this situation is that the psychiatrist actually has been dispensing psychotropic medications irresponsibly to the detriment of Tony and other agency clients. In general, counselors have an obligation to monitor the ethical behavior within the organizations in which they are employed (IAMFC, 2005, Section A.8). Tony's counselor should first evaluate carefully whether unethical practices are occurring, using special caution to ensure that his personal beliefs about the psychiatrist do not influence this evaluation. If this counselor concludes that unethical psychiatric practices are occurring within this agency, the counselor should report these alleged ethical violations to the supervisory administration of the agency (ACA, 2005, Section H.2.e). If the issue is not resolved at this level, the counselor may also consider reporting an ethical complaint to 
the psychiatrist's state licensure board and the ethics committees of the professional organizations to which she belongs (IAMFC, 2005, Section H.2). In addition, unethical organizational practices may need to be reported to the agency's accreditation body or funding source.

Finally, the counselor may wish to support Tony's parents' concern about the medical treatment of their son. If so, Breggin and Cohen (1999) offered a number of suggestions for counselors who find themselves in such a position. These suggestions included the following:

1. Inform your clients about the prevailing biopsychiatric viewpoint.

2. Clarify the reasons for which you do not professionally agree with or encourage the use of medication.

3. Recommend consultations and readings from both viewpoints.

4. Do not pressure your clients to go along with your particular philosophy of therapy.

5. Avoid making referrals for psychiatric drugs if you believe they will not be helpful.

6. Unless they have been taking drugs for a very short time, always warn clients about the dangers of abruptly stopping any psychiatric medication.

7. If you have knowledge about adverse effects, share it with your clients.

8. If you are a nonmedical therapist with clients who want to withdraw from drugs, consider referring them to a physician.

9. If your clients are favorably inclined, consider involving their families, friends, and other resources [during the withdrawal process].

10. If the therapy is not going well and cannot be fixed, refer the client to another therapist rather than encouraging the use of psychiatric drugs.

11. Make notes in your therapy record to indicate that you have had conversations with your clients about drugs. (pp. 198-201)

CASE STUDY 3: MR. AND MRS. TAYLOR

Mr. and Mrs. Taylor presented for couples counseling in the private practice office of a couple and family counselor who practices from a family systems theoretical framework. The couple's primary presenting problem involved conflict about their sexual relationship, finances, and parenting. The Taylors have two children, ages 13 and 10. Mrs. Taylor is a 42-year-old part-time substitute teacher in the local school district. Mr. Taylor is a 43-year-old business associate who has been treated for recurrent major depressive disorder for the past 15 years. During that time, Mr. Taylor has made bimonthly visits to a psychiatrist who prescribed an antidepressant medication. He has tried unsuccessfully to taper off the medication in the past 5 years. Each time the psychiatrist reduced Mr. Taylor's dosages, his depressive symptoms returned to a higher level, leading the psychiatrist to return to prescribing the higher doses of medication.

The couple stated that they were most frustrated by their sexual relationship problems. In their intake session, Mrs. Taylor stated, "When I talk with my girlfriends, they all seem to be having great sex with their husbands! It makes me so depressed that we haven't even had any sex for the past 3 years!" Mr. Taylor responded, "She just doesn't understand that it's not that easy for me. I have absolutely no interest in sex right now. It doesn't have anything to do with her-I just can't make myself to feel something that I don't!' Both partners agreed that their entire 17-year marriage has been characterized by "infrequent, unsatisfying sex." It became clear that 
both partners thought that Mr. Taylor was the primary problem and that if he "could just get better, things would be different." Further assessment revealed that Mr. Taylor had briefly attempted to take an erectile dysfunction medication (examples of this class of drugs include Viagra, Cialis, and Levitra). However, he noticed very few changes based on that medication, so he discontinued its use.

Mrs. Taylor indicated during the intake assessment that she believed her husband's low level of sexual desire was "at least partly due to those medications he takes." She expressed that she has grown to resent her husband's depression and his medications, viewing them as "excuses to avoid dealing with life and with me." Currently, she is considering a divorce but states that she would be afraid to leave him because she's not sure he could survive without her. Overall, she knows that she is not happy and wants the situation to change, but she's not certain about which direction she wants to take.

\section{Commentary}

Three pertinent ethical issues arise in this case study: identifying the client, attending to the systemic context, and the client's access to information.

Identifying "the client." The first ethical issue relates to defining who "the client" in this situation is. The ACA (2005) Code of Ethics states, "When a counselor agrees to provide counseling services to two or more persons who have a relationship, the counselor clarifies at the outset which person or persons are clients and the nature of the relationships the counselor will have with each involved person" (Section A.7). The IAMFC (2005) Ethical Code also addresses this issue, stating,

Marriage and family counselors have an obligation to determine and inform counseling participants who is identified as the primary client. The marriage and family counselor should make clear when there are obligations to an individual, a couple, a family, a third party, or an institution. (Section A.7)

Because the couple presented for couples counseling, it appears in this situation that the couple is the client. However, the partners' individual concerns complicate this issue and may render it more beneficial to identify one of the partners as the primary client. Mrs. Taylor appears to be the partner who is most motivated to change, especially because of the high level of frustration and indecision she is experiencing. Alternatively, both partners clearly identify Mr. Taylor as the source of the couple's problems. Therefore, this counselor must clarify with the couple their treatment goals and expectations about which one of them will be identified as the client throughout treatment.

Systemic context. A related ethical issue for this couple and family counselor involves the partners' tendency to locate the source of their relationship problems within an individual—namely, Mr. Taylor. The IAMFC (2005) Ethical Code asserts, "Recognizing the origins of marriage and family counseling in systems thinking, they avoid whenever possible assigning problems to individuals" (Section E, Introduction). This may prove challenging for this counselor, especially because both partners agree that Mr. Taylor is the cause of the relationship problems. The fact that Mr. Taylor has been diagnosed with a mental illness and is taking psychotropic medication for this condition further reinforces the notion that Mr. Taylor has the problem (Liburd \& Rothblum, 1995; Prosky \& Keith, 2003). Because this counselor's work is grounded in family systems theory, she is likely to believe that the couple's relationship problems are rooted in the relational context (Guttman, 1991). This belief about the nature of the problem may run counter to the couple's expectations for treatment. Therefore, this counselor should explain her treatment approach to the clients so they can make an informed decision as to whether they wish to continue treatment with her (ACA, 2005, Section A.2.b).

Client access to information. The third relevant ethical issue relates to the client's need for information and the counselor's role in providing that information. The counselor should begin by assessing the degree to which Mr. and Mrs. Taylor understand the meaning of his diagnosis of major depressive disorder (ACA, 2005, Section A.2.b) as well as the amount of information he has been given about the psychotropic medication he takes. If Mr. Taylor appears to have limited understanding about his diagnosis and medications, the counselor can assist 
the client in gathering information to increase his knowledge in these areas (ACA, 2005, Section A.2.b). For example, Mr. Taylor may need additional information about treatment alternatives for his disorder, possible side effects of the medication he takes (including potential sexual side effects; Taylor, Rudkin \& Hawton, 2005) and withdrawal symptoms, which might help to explain his cycle of experiencing increased symptoms on tapering off the medications (Glenmullen, 2000, 2005). Because it appears that Mr. Taylor continues to receive treatment from his psychiatrist, the counselor should seek written consent to contact the psychiatrist to coordinate treatment and gain further information about his treatment history (ACA, 2005, Section A.3). Finally, it may be beneficial for Mr. Taylor to be examined by a physician to rule out a physiological basis for his sexual dysfunction and gather additional information about his physical functioning, in which case the counselor should also seek permission to contact that person (ACA, 2005, Section A.3).

\section{CONCLUSION}

The field of couple and family counseling and therapy has long had a tenuous association with the prescription of psychotropic medications (Prosky \& Keith, 2003). For example, therapists practicing from a Milan systemic frame-work approached clients who wished to take psychotropic medications with a perspective of "This medication may make you feel better for a while but will not change you" (Campbell, Draper, \& Crutchley, 1991, p. 344). Likewise, in a discussion of symbolic-experiential family therapy, Roberto (1991) wrote that "the dominant danger in the use of psychotropic medication, aside from the physiological side effects, is the selfreinforcing nature of medication use; if medication decreases distress, then the problem must be a need for medication" (p. 457). The underlying tension surrounding this issue relates to the systemic orientation of couple and family counselors in family systems theory (IAMFC, 2005, Section A). A value conflict results from the distinct assumptions of family systems theory (i.e., problems lie within the relational context) and psychopharmacology (i.e., problems lie within an individual and specifically within their physiology). Nonetheless, couple and family counselors and clients are likely to demonstrate a wide range of perspectives in their beliefs toward the utility of psychotropic medications in the treatment of mental health disorders. Therefore, couple and family counselors should be prepared to address the ethical challenges that surround issues related to psychopharmacology.

\section{REFERENCES}

American Academy of Pediatrics. (2001). Clinical practice guidelines: Treatment of the school-aged child with attention-deficit/hyperactivity disorder. Pediatrics, 108, 1033-1044.

American Counseling Association. (2005). ACA code of ethics. Alexandria, VA: Author.

Aschenbrenner, D. S. (2005). Atypical antipsychotics: A warning [Abstract]. American Journal of Nursing, 105, 25-28.

Beitman, B. D., \& Saveanu, R. V. (2005). Integrating pharmacotherapy and psychotherapy. In J. E. Norcross (Ed.), Handbook of psychotherapy integration (2nd ed., pp. 417-436). New York: Oxford University Press. Blanco, C. (2005). Evidence-based pharmacotherapy of social anxiety disorder. CNS Spectrums, 10, 10-11. Bovasso, G. B., Eaton, W. W., \& Armenian, H. K. (1999). The long-term outcomes of mental health treatment in a population-based study.

Journal of Consulting and Clinical Psychology, 67, 529-538. Breggin, P. R. (199 1). Toxic psychiatry. New York: St. Martin's. Breggin, P. R., \& Cohen, D. (1999). Your drug may be your problem: How and why to stop taking psychiatric medications. Cambridge, MA: Da Capo.

Campbell, D., Draper, R., \& Crutchley, E. (1991). The Milan systemic approach to family therapy. In A. S. Gurman \& D. P. Kniskern (Eds.), Handbook of family therapy: Vol. II (pp. 325 -3 62). New York: Brunner/ Mazel.

Canadian Psychiatric Association. (2005). Pharmacotherapy. Canadian Journal of Psychiatry, 50, 19-28. Chavira, D. A., \& Stein, M. B. (2002). Combined psychoeducation and treatment with selective serotonin reuptake inhibitors for youth with generalized social anxiety disorder. Journal of Child and Adolescent Psychopharmacology, 12, 47-54.

Chouinard, G. (2004). Issues in the clinical use of benzodiazepines: Potency, withdrawal, and rebound [Abstract]. Journal of Clinical Psychiatry, 65, 7-21. 
Crews, J. A., \& Hill, N. R. (2005). Diagnosis in marriage and family counseling: An ethical double bind. The Family Journal: Counseling and Therapy for Couples and Families, 13, 63-66.

Dorman, D. (2003). Dante's cure: A journey out of madness. New York: Other Press.

Finn, R. (2001). Benzodiazepines steal patient memory of CBT (cognitive behavioral therapy). Clinical Psychiatry News, 29, 11.

Glasser, W. (2003). Warning: Psychiatry can be hazardous to your mental health. New York: Quill.

Glenmullen, J. (2000). Prozac backlash: Overcoming the dangers of Prozac, Zoloft, Paxil, and other antidepressants with safe, effective alternatives. New York: Simon \& Schuster.

Glenmullen, J. (2005). The antidepressant solution: A step-by-step guide to safely overcoming antidepressant withdrawal, dependence, and "addiction. ”New York: Free Press.

Graybar, S. R., \& Leonard, L. M. (2005). In defense of listening. American Journal of Psychotherapy, 59, 1-18. Guttman, H. A. (1991). Systems theory, cybernetics, and epistemology. In A. S. Gurman \& D. P. Kniskern (Eds.), Handbook of family therapy: Vol. II (pp. 41-61). New York: Brunner/Mazel.

Hansen, J. T. (2005). The devaluation of inner subjective experiences by the counseling profession: A plea to reclaim the essence of the profession. Journal of Counseling and Development, 83, 406-415.

Healy, D. (2002). The creation of psychopharmacology. Cambridge, MA: Harvard University Press.

Hill, N. R., \& Crews, J. A. (2005). The application of an ethical lens to the issue of diagnosis in marriage and family counseling. The Family Journal, 13,176-180.

Hollon, S. D., Jarrett, R. B., Nierenberg, A. A., Thase, M. E., Trivedi, M., \& Rush, A. J. (2005). Psychotherapy and medication in the treatment of adult and geriatric depression: Which monotherapy or combined treatment? Journal of Clinical Psychiatry, 66, 455-468.

Hollon, S. D., Thase, M. E., \& Markowitz, J. C. (2002). Treatment and prevention of depression. Psychological Science in the Public Interest, 3,39-77.

Ingersoll, R. E. (2000). Teaching a psychopharmacology course to counselors: Justification, structure, and methods. Counselor Education \& Supervision, 40, 58-69.

International Association of Marriage and Family Counselors (IAMFC). (2005). Ethical code of the International Association of Marriage and Family Counselors (IAMFC). Retrieved January 31, 2006, from http://www.iamfc.com/ethical__ codes.html

Jackson, G. (2005). Rethinking psychiatric drugs: A guide for informed consent. Bloomington, IN:

AuthorHouse.

Keefe, R. S. E., Silva, S. G., Perkins, D. O., \& Lieberman, J. A. (1999). The effects of atypical antipsychotic drugs on neurocognitive impairment in schizophrenia: A review and meta-analysis. Schizophrenia Bulletin, 25, 201-222.

King, J. H., \& Anderson, S. M. (2004). Therapeutic implications of pharmacotherapy: Current trends and ethical issues. Journal of Counseling and Development, 82, 329-336.

Kirsch, I., Moore, T. J., Scoboria, A., \& Nicholls, S. S. (2002). The emperor's new drugs: An analysis of antidepressant medication data submitted to the U.S. Food and Drug Administration. Prevention \& Treatment, 23. Retrieved December 5, 2005, from

http://www.journals .apa.org/prevention/volume5/pre0050023a.html

Liburd, R., \& Rothblum, E. (1995). The medical model. In E. J. Rave \& C. C. Larson's (Eds.), Ethical decision making in therapy: Feminist perspectives (pp. 177-201). New York: Guilford.

Lin, P., Campbell, D. G., Chaney, E. F., Liu, C. F., Heagerty, P., \& Hedrick, S. (2005). The influence of patient preference on depression treatment in primary care. Annals of Behavioral Medicine, 30, 164-173.

Lutova, N. B. (2002). Specific interrelationship of combined psychopharmacotherapy and psychotherapy in the treatment of mentally ill patients. International Journal of Mental Health, 31, 98-106.

Moncrieff, J., \& Kirsch, I. (2005). Efficacy of antidepressants in adults. British Medical Journal, 331, 155-157. Murray, T. L. (in press). The other side of psychopharmacology: A review of the literature. Journal of Mental Health Counseling.

Paradise, L. V., \& Kirby, P. C. (2005). The treatment and prevention of depression: Implications for counseling and counselor training. Journal of Counseling and Development, 83, 116-119.

Preston, J. D., O’Neal, J. H., \& Talago, M. C. (2000). Handbook of clinical psychopharmacology for therapists. Oakland, CA: New Harbinger. 
Prosky, P. S., \& Keith, D. V. (Eds.). (2003). Family therapy as an alternative to medication: An appraisal of Pharmland. New York: Brunner-Routledge.

Roberto, L. G. (199 1). Symbolic-experiential family therapy. In A. S. Gurman \& D. P. Kniskern (Eds.), Handbook of family therapy: Vol. II (pp. 444- 476). New York: Brunner/Mazel.

Safer, D. J. (2002). Design and reporting modifications in industry-sponsored comparative psychopharmacology trials. The Journal of Nervous and Mental Disorders, 190, 583-592.

Schwartz, R. A. (2005). How safe is long-term benzodiazepine pharmacotherapy? Journal of Clinical Psychopharmacology, 25, 624-625.

Scovel, K. A., Christensen, O. J., \& England, J. T. (2002). Mental health counselors' perceptions regarding psychopharmacological prescriptive rights. Journal of Mental Health Counseling, 24, 36-50.

Shattell, M., \& Keltner, N. L. (2004). The case for atypical antipsychotics in bipolar disorder. Perspectives in Psychiatric Care, 40, 34-38.

Steiner, M., Pearlstein, T., Cohen, L., Endicott, J., Kornstein, S., Roberts, C., et al. (2006). Expert guidelines for the treatment of severe PMS, PMDD, and comorbidities: The role of SSRIs. Journal of Women's Health, 15, 57-69.

Taylor, M. J., Rudkin, L., \& Hawton, K. (2005). Strategies for managing antidepressant-induced sexual dysfunction: Systematic review of randomized control trials. Journal of Affective Disorders, 88, 241-254. Tremblay, P., \& Blier, P. (2006). Catecholaminergic strategies for the treatment of major depression. Current Drug Targets, 7, 149-158.

Trestman, R. L. (2004). Optimism grows for combined treatment of severe personality disorder. Psychiatric Times, 21, 35-40.

Van Ameringen, M., Mancini, C., Patterson, B., \& Bennett, M. (2006). Topiramate augmentation in treatmentresistant obsessive-compulsive disorder: A retrospective, open-label case series. Depression \& Anxiety, 23,1-5. Winston, A., Been, H., \& Serby, M. (2005). Psychotherapy and psychopharmacology: Different universes or an integrated future. Journal of Psychotherapy Integration, 15, 213-223. 